\title{
LER PARA SER: A LEITURA NA PERSPECTIVA FREIREANA
}

José Cavalcante Lacerda Junior ${ }^{1}$

Maria Inês Gasparetto Higuchi ${ }^{2}$

\section{Resumo}

O texto apresenta uma reflexão sobre a leitura à luz da concepção de Paulo Freire, que a infere como prática social capaz de levar o sujeito a compreender os intercursos ideológicos da realidade. Nesse sentido, o mesmo objetiva compreender a importância da leitura tendo como parâmetro a perspectiva de Paulo Freire. Para tanto, sua construção metodológica pautou-se em uma pesquisa bibliográfica, a qual investigou o campo teórico-conceitual da leitura, trançando uma reflexão a partir de Freire (1987; 1996; 2001; 2003). Desse modo, como resultado, a interface entre leitura e o pensamento freireano sinaliza a necessidade de explicitar o ato de ler como via de construção de uma consciência individual e coletiva acerca das tramas que atravessam a realidade. Assim, a intenção proposta é propiciar a consideração imprescindível da leitura na construção de um ser humano crítico e instrumentalizado para transformação ideológica da sociedade.

Palavras-Chave: Realidade; Leitura; Paulo Freire; Aprender; Ler

\section{READING TO BE: READING IN FREIRE'S PERSPECTIVE}

\author{
Abstract \\ ${ }^{1}$ Doutorando em Ciências do Ambiente e Sustentabilidade na Amazônia pelo Programa de Pós-Graduação em \\ Ciências do Ambiente e Sustentabilidade na Amazônia - PPGCASA da Universidade Federal do Amazonas - \\ UFAM. Endereço: Avenida Pedro Teixeira, 2565, Chapada, CEP: 69050085 - Manaus, AM - Brasil. E-mail: \\ psi.josecavalcante@gmail.com \\ ${ }^{2}$ Doutora em Antropologia Social - Brunel University of London (1999). Endereço: Avenida André Araújo, \\ 2936, Aleixo, CEP: 69080000 - Manaus, AM - Brasil. E-mail: higuchi.mig@gmail.com \\ Revista Reflexão e Ação, Santa Cruz do Sul, v. 25, n. 2, p. 101-118, Maio./Ago. 2017. \\ http://online.unisc.br/seer/index.php/reflex/index
}


The text presents a reflection on reading in the light of Paulo Freire's conception, which infers it as a social practice capable of understanding the ideological interchanges of reality. In this sense, the objective is to understand the importance of reading with Paulo Freire's perspective as a parameter. To that end, its methodological construction was based on a bibliographical research, which investigated the theoretical-conceptual field of reading, drawing a reflection from Freire $(1987 ; 1996 ; 2001 ; 2003)$. Thus, as a result, the interface between reading and Freire's thought signals the need to understand the act of reading as a way of building an individual and collective consciousness about the plots that cross reality. Thus, the proposed intention is to provide the essential consideration of reading in the construction of a critical and instrumental human being for the ideological transformation of society.

Keywords: Reality; Reading; Paulo Freire; Learn; To Be

\section{LEER PARA SER: LECTURA EN PERSPECTIVA FREIRENO}

\section{Resumen}

Este artículo presenta una reflexión sobre la luz de lectura para el diseño de Paulo Freire, que infiere como práctica social puede comprender la realidad las relaciones ideológico. En este sentido, se pretende comprender la importancia de la lectura teniendo como parámetro la perspectiva de Paulo Freire. Por lo tanto, su construcción metodológica fue marcado en una investigación bibliográfica, que investigó el campo teórico y conceptual de la lectura, trenzando un reflejo de Freire (1987; 1996; 2001; 2003). Por lo tanto, como resultado, la interfaz entre la lectura y el pensamiento de Freire indica la necesidad de comprender el acto de la lectura como una forma de construir la conciencia individual y colectiva sobre las parcelas que se ejecutan a través de la realidad. Por lo tanto, la propuesta tiene por objeto proporcionar consideración esencial de lectura en la construcción de un ser humano crítico y instrumentalizada para la transformación ideológica de la sociedad.

Palabras-clave: Realidad; Lectura; Paulo Freire; Aprender; Ser

\section{INTRODUÇÃO}


Ler significa representar a afirmação do sujeito, de sua história como produtor de linguagem e de sua singularização como intérprete do mundo que o cerca (FREIRE, 2003). A prática da leitura, além de ser um cultivo pessoal, é também motivada por políticas públicas, que possibitam a criação de espaços próprios, como bibliotecas, e a acessibilidade para a população, via compra e disponibilização de livros. Nesse sentido, o espaço da escola configura-se como lócus privilegiado para incentivar os educandos quanto à necessidade de adquirir-se o hábito da leitura, pois através deste instrumental, pode-se despertar consciências críticas e libertadoras, onde se assentam verdadeiras esperanças de mudanças, principalmente sociais.

Nesta conjuntura, é interessante buscar a contribuição de Paulo Freire. Ora, para Freire (2003) conhecer a realidade consiste em lê-la com um aguçado olhar e lançar-se às mudanças, tendo em vista que nosso mundo hodierno é marcado pelo abismo da desigualdade. Leitura significa conhecimento, e o conhecimento, por sua vez é transformador. Para tanto, torna-se imprescindível a construção de uma perspectiva em que o ser humano se aproprie da leitura como uma prática de elucidação e visualização da dinâmica social. Isto é, construir condições de leitura dos códigos linguísticos que efetuam as relações sociais, mas, fundamentalmente, a leitura dos meandros ideológicos que perpassam os enlaces sociais.

O sujeito que lê se descobre capaz de transformar a realidade social na qual está inserido a partir de um sonho e um projeto de mudança tecido no diálogo entre o seu mundo e o mundo da coletividade. Nesse processo não se busca apenas a continuação de um sistema mecânico reprodutor, mas de consciências individuais críticas, que levem o coletivo a uma igualdade de condições sociais.

Com efeito, a abordagem do presente artigo parte do seguinte problema: qual a importância da leitura na construção crítica do indivíduo contemporâneo? Visando problematizar essa realidade, nos desbruçamos em compreender a relevância da concepção de leitura sob a ótica freireana. Articulando tal finalidade, buscou-se dessa forma, identificar algumas características do cenário contemporâneo que sustenta a construção do sujeito hoje, bem como conhecer o conceito de leitura mediante a abordagem freireana.

Nessa perspectiva, o texto organiza-se, abaixo, em quatro tópicos, a saber: 1) Características da realidade contemporânea, onde se apontam algumas singularidades do cotidiano; 2) $\mathrm{O}$ ato de ler, o qual destaca, brevemente, a relevância da leitura em nosso contexto; 3) A Leitura a partir da perspectiva freireana, que visa apresentar a relevância da leitura na vida de Paulo Freire, bem como a sua concepção acerca do tema; 4) Do ler para o 
ser, objetivando destacar a importância da leitura na construção de um ser crítico, tendo leitura como acontecimento privilegiado no cenário contemporâneo.

Assim, acredita-se que os dados advindos do presente estudo possibilitam uma reflexão acerca do pensamento freireano mediante sua interface com a leitura. Assim, oportuniza referendar a relevância de uma compreensão dos meandros da realidade como elemento que colabora na construção de uma consciência social e crítica.

\section{CARACTERÍSTICAS DA REALIDADE CONTEMPORÂNEO}

A modernidade se dá na afirmação antropocêntrica frente à religiosidade cristã (REALE, 1991). Essa perspectiva proporcionou na seara social a elaboração de novos conceitos, teorias e métodos. A concepção em voga de cultura e natureza reposiciona o lugar do homem no universo e tal situação reclama novas respostas. As fontes que até então eram vigentes, fideísmo e teocentrismo, gradativamente vão sendo substituídas e o indivíduo racional se descobre como única resposta. É na razão subjetiva que se constituirá a nova concepção de conhecimento, encabeçada pelo taxativo Descartes (1999): penso, logo existo.

Esta crença moderna conduz o ser humano a um fracasso, pois não conseguiu explicar os problemas e nem esclareceu as complexas estruturas do homem moderno no mundo. Ortega (1982, p.36) constata que “o humano escapa à razão físico-matemática como a água por uma peneira" e declara a necessidade de se pensar nas estruturas, a partir da vida, isto é, da espontaneidade, da sensibilidade e das ações concretas emergentes do viver diário. Harvey (1993) explicita que a modernidade, enquanto projeto iluminista, possui a dificuldade de se erguer na irônica ilusão da racionalidade, conforme as críticas de Weber, Nietzsche e Rousseau. Imerso na desconfiança, há um abalo e uma perda de segurança sobre as crenças e propostas da modernidade.

Sob tal ótica, reconhece-se que o progresso racional da modernidade não se cumpriu. Problemas de cunho existencial se propagaram encontrando terreno fértil na forte tendência em banalizar a vida, a qual é tratada como algo descartável, onde os não-aptos são abocanhados pelo sistema de produção capitalista, gerando um descontentamento para com a modernidade. Para além de um descontentamento, as rápidas transformações no último século e no início deste, atingiram todos os aspectos do ser humano, modificando o seu cotidiano, sua forma de estar e representar no mundo. A modernidade, essencialmente industrializada e materializada, vem se moldando mediante a produção de bens intangíveis, isto é, a produção de bens materiais ganha um formato de desenvolvimento de produtos, de gestão, de Revista Reflexão e Ação, Santa Cruz do Sul, v. 25, n. 2, p. 102-118, Maio./Ago. 2017.

http://online.unisc.br/seer/index.php/reflex/index 
conhecimento acessível a poucos. Contudo, embora essa transição seja explícita, a essência da modernidade capitalista se mantém: produção de mercadoria e lucro. Muda-se a forma, mas se mantém a essência.

Por isso, não se cumpre em afirmar uma "pós-modernidade" como uma nova configuração temporal hoje. Não há uma ruptura com os elementos que conformam o paradigma moderno, mas trata-se de uma transformação dentro de uma estrutura contínua pautada no sistema econômico vigente, o capitalismo. A modernidade se reconfigura e ganha novas nuances. Bauman (2001) utiliza a expressão modernidade líquida como uma metáfora para afirmar o caráter fluido das instituições, estruturas e relações que configuraram um ser humano centrado no individualismo que aparta de si o cuidado para com aquilo que está ao seu entorno, inclusive o ambiente. É essa expressão que orienta a compreensão do contexto moderno atual: modernidade líquida.

Para exemplificar o contexto contemporâneo, Bauman (2001) evoca o pensamento de Marcurse (2001, p.23), que afirma: "o problema que enfrentamos é a necessidade de nos libertarmos de uma sociedade que desenvolve em grande medida as necessidades materiais", por isso, apresenta que ser moderno, hoje, significa: 1) Colapso da antiga ilusão: a história é racional; 2) Privatização das tarefas e deveres. Assim, a sociedade de indivíduos promove a desintegração da cidadania.

Conforme se observa, a fase líquida moderna possui uma configuração da identidade impulsionada pelo desejo, que desagua numa teia da indústria cultural que fomenta, através do consumo, a busca constante por realizações pessoais e sociais. Somos, dessa maneira, uma sociedade consumista e individualizada, onde a quebra dos vínculos coletivos projeta um indivíduo deprimido e solitário. O capitalismo leve gera o desmantelamento das redes protetivas e normativas da sociedade, concentrando no indivíduo, e somente nele, o agente responsável pela vida. Livros de autoajuda, conselhos e orientações, por exemplo, tornam-se um vício e colaboram no ciclo do consumo.

O novo arranjo líquido remodela a relação do sujeito com o Estado. Atravessada pelo consumo, a comunidade passa a ser um território de livre comércio global, onde o capitalismo devora o Estado e as multinacionais abocanham as relações. Assim, conforme Bauman (2001), estamos inseridos uma nova fase da modernidade que surgiu com o derretimento dos grilhões que aprisionavam a liberdade individual de escolher e agir que só seria sanada com a flexibilização, a desregulamentação e a liberação do mercado. Nesse sentido, a modernidade líquida configura um indivíduo que se consolida quando deseja e consome, construindo uma identidade volátil e instável.

Revista Reflexão e Ação, Santa Cruz do Sul, v. 25, n. 2, p. 102-118, Maio./Ago. 2017. http://online.unisc.br/seer/index.php/reflex/index 
Dessa maneira, o decurso da modernidade evidencia que com a busca de conhecer aquilo que é próprio do ser humano, acabou por produzir uma concepção mecânica e fragmentada, visualizada na concepção cartesiana de ser humano. A visão mecanicista nutriu as concepções filosóficas da modernidade que proporcionou uma compreensão do ser humano e, consequentemente, a análise dualista cartesiana sobrepôs o ser humano (sujeito racional) ao ambiente (objeto passivo).

Para além dessa perspectiva, vive-se, hoje, a era da "pós-verdade". Tida como a expressão inglesa, post-truth, do ano de 2016, o termo "pós-verdade" foi elucidado pelo Dicionário Oxford em 2016 como um adjetivo que se relaciona ou denota circunstâncias nas quais fatos objetivos têm menos influência na configuração da opinião pública do que aspectos emotivos e crenças subjetivas ${ }^{3}$. Isto é, imerso nas redes de informações, cada vez mais contínuas e líquidas, o uso das palavras e a manipulação dos fatos afasta cada vez mais a veracidade para relativizar as fontes de onde emana o conhecimento.

O ritmo acelerado das informações, a fluidez do conhecimento e a sobreposição de antigos paradigmas convocam um repensar das práticas científicas e a necessidade de uma leitura dos meandros ideológicos que questione a origem dos conceitos que circulam em nosso dia-a-dia. Por conseguinte, se estabelece a necessidade constante de rever e atualizar os conceitos que auxiliam na percepção acerca do mundo marcado pelas constantes modificações do saber globalizado. Mais ainda, torna-se fundamental identificar a origem das informações, pois, uma das características do contexto contemporâneo é o papel despótico da informação manipulada que atende aos interesses específicos de grupos políticos (SANTOS, 2004).

[...] as novas condições técnicas deveriam permitir a ampliação do conhecimento do planeta, dos objetos que o forma, das sociedades que o habitam e dos homens em sua realidade intrínseca. Todavia, nas condições atuais, as técnicas de informação são principalmente utilizadas por um punhado de atores em função de seus objetivos particulares. [...] O que é transmitido à maioria da humanidade é, de fato, uma informação manipulada que, em lugar de esclarecer, confunde. (SANTOS, 2004, p.38-39).

Assim, assentando a reflexão acerca da dinâmica contemporânea, pode-se indicar que tanto concepções quanto práticas não podem se constituir em padronizações que enrijeçam e se cristalizam. O movimento sociocultural é fluido! O reconhecimento de que nosso atual

3 Na versão on line Post-Truth. Adjective. Relating to or denoting circumstances in which objective facts are less influential in shaping public opinion than appeals to emotion and personal belief: "In this era of post-truth politics, it's easy to cherry-pick data and come to whatever conclusion you desire". "Some commentators have observed that we are living in a post-truth age". (OXFORD LIVING DICTIONARIES, 2017. In.: https://en.oxforddictionaries.com/definition/post-truth).

Revista Reflexão e Ação, Santa Cruz do Sul, v. 25, n. 2, p. 102-118, Maio./Ago. 2017.

http://online.unisc.br/seer/index.php/reflex/index 
contexto passa por significativas transformações, estimula novos olhares, mas, fundamentalmente, a capacidade de analisar as configurações e processos que atravessam tais concepções, bem como o desenvolvimento de outros fazeres. Daí a urgência de situar a leitura da visão freireana da realidade como condição indispensável no processo educativo libertador.

\title{
3 O ATO DE LER
}

A prática da leitura na realidade social brasileira é incipiente. Luckesi (2001) aponta que desde o Período Colonial a leitura é tida como um instrumento de divisão social entre os senhores e os escravos. Segundo ele:

\begin{abstract}
A história da leitura entre nós, por conseguinte, se inicia com uma violenta discriminação: aos senhores era assegurado esse direito; aos outros, que nas suas culturas de origem certamente já o exerciam, era usurpado este mesmo direito, em nome da superioridade da raça dos que aqui aportaram como 'descobridores e benfeitores'. (LUCKESI, 2001, p. 127).
\end{abstract}

Nota-se, ainda, que os conteúdos destinados à maioria do público passavam pelo crivo dos grupos dominantes, que selecionavam as informações e o conhecimento, justamente para evitar o questionamento da ordem e dos interesses. Consequentemente, tornava-se inviável a leitura da realidade a partir da visão dos dominados, pois, a confrontação das informações com as experiências encontrava-se prejudicada pela leitura seletiva a eles (dominados) apresentada. Tal prática continuou no decorrer de nossa história. Luckesi (2001, p. 29) continua:

\begin{abstract}
As discriminações continuam em relação aos sujeitos aos quais é reconhecido, na prática e não apenas nas leis, o direito de ler. Por ocasião do Segundo Congresso de Leitura do Brasil, em 1979, sob os auspícios da Universidade Estadual de Campinas, SP, o prof. Ezequiel Theodoro, em seu discurso de abertura, assim se expressava, criticando a atual situação de leitura no país: 'Somente a elite dirigente deve ler. O povo deve ser mantido fora e longe dos livros. Os livros estimulam a criticidade e a transformação - elementos que vão contra o modelo de desenvolvimento proposto pelo governo'.
\end{abstract}

Verifica-se que a leitura no Brasil pauta-se, então, por uma prática discriminatória. Alguns leem e a outros é usurpada esta ferramenta de entendimento social, pois, retira-se o direito de se informar e a capacidade de ler a própria realidade. A alienação estabelecida em nossa história parece ainda resistir em nosso tempo, embora com outra formatação. Segundo Lucksei (2001, p. 132) “o cinema e a televisão, com seus enlatados, importados na sua 
maioria dos países que nos dominam, veiculam o conteúdo de 'leitura de realidade' que a eles interessa para nos manipular e instrumentalizar, sub-repticiamente, a cada dia que passa."

Diante desta conjuntura, a leitura apresenta-se como uma necessidade, ou seja, é uma ferramenta útil e inevitável para a construção de um ser crítico e reflexivo diante da atual sociedade. Pensar as ideologias que compõem nossa circunstância histórica exige um cabedal de conhecimento que esteja ligado à contextualização histórica dos problemas e dos fatos.

A manipulação das massas e manutenção das elites são projetos que, hoje, o ser humano moderno, não pode mais admitir. O sujeito consciente de sua responsabilidade, individual e coletiva, deve perpassar um campo de construção de uma identidade pautada pela ética e pela consciência crítica. As palavras que estão entremeadas nas redes ideológicas do sistema social devem ser lidas numa perspectiva libertadora, na qual o ser humano, revestido de sujeito da história, não compactue com a manutenção de um status que só afunila a diferença entre "senhores" e "servos". Assim, faz-se necessária a leitura como ferramenta imprescindível na construção do ser humano hoje. Afirma-se, desta forma, a autonomia do sujeito no mundo, a pessoa humana como agente da história. $\mathrm{O}$ ser é chamado a assumir a responsabilidade pelo que acontece no mundo.

A leitura não é uma tarefa fácil. Ler demanda hábito e compreensão dos códigos linguísticos. Para Soares (1995, p. 8 e 9) "ler é um processo de relacionamento entre símbolos escritos e unidades sonoras, e é também um processo de construção da interpretação de textos escrito." A apropiação da leitura, através de um constante exercitar, pode transformar a compreensão que o sujeito tem de si e do mundo que o cerca. Nisto, é imprescindível inserir o educando no mundo da leitura, no constante desejo de decifrar e interpretar o sentido dos textos e dos contextos. A leitura mobiliza um projeto de vida movido pela curiosidade, pelo desejo de crescer. A pessoa se renova constantemente ampliando sua visão de mundo, compreendendo os meandros daquilo que ouve e vê do sistema em que está inserido.

Neste empreendimento a ajuda do educador é imprescíndivel. A tarefa não é fácil, é árdua e profunda, pois, as crianças chegam à escola com a leitura do seu mundo particular. Respeitar o conhecimento que já possuem é o primeiro passo para que o educador comece a construção de um pensamento mais crítico e elaborado.

O encantamento pela leitura favorece o desenvolvimento de um relacionamento prazeroso com o texto. A construção do hábito da leitura no contexto escolar deve ser de forma dinâmica e agradável, utilizando-se de aspectos como a socialização, integração e ludicidade para a instalação do gosto de ler, que se adquire com a prática e exercícios constantes. Pode-se falar que há um relacionamento entre leitor e texto. Ler é compreender. Revista Reflexão e Ação, Santa Cruz do Sul, v. 25, n. 2, p. 102-118, Maio./Ago. 2017.

http://online.unisc.br/seer/index.php/reflex/index 
Mas, para tal é preciso que o leitor esteja comprometido com sua leitura, mantendo um posicionamento crítico sobre o que lê. Quando atende a essa necessidade, o leitor se projeta no texto, levando para dentro dele toda sua vivência pessoal, com suas emoções, expectativas, seus preconceitos etc. É por isso que consegue ser tocado pela leitura.

\begin{abstract}
É na passagem da decodificação das palavras para a compreensão do que está escrito que está a certificação do leitor ideal, ou seja, aquele que é capaz de compreender e não de apenas memorizar a mensagem - fazendo uma avaliação e um constante questionamento do que leu. No entanto, esse processo requer condições favoráveis para adequar uma série de fatores, conforme citou a autora na segunda caracterização. O professor mediador da leitura é intérprete de um mundo repleto de aventuras, que permitem o estudante alargar as fronteiras de seu próprio mundo. Com a colaboração do professor - agente transformador - o aluno descobre que a leitura lhe permite viver experiências, sentimentos de alegria, de tristeza, de medo, de angústia e de encantamento, como também lhe proporciona construir conhecimentos mais elaborado e significativo da realidade, desde que adote uma prática metódica e crítica para o ato de ler. (PICANÇO, 2009, p. 1).
\end{abstract}

Contudo, não se deve confundir o prazer da leitura de um texto com a facilitação quanto ao tipo de leitura que o aluno deseja. Nota-se que os professores, com o intuito de incentivar a prática da leitura, rendem-se ao "gosto" da literatura da moda (MAGNAMI, 2009). Esta prática de leitura presta um desserviço ao objetivo da leitura de colaborar na formação de cidadãos conscientes e críticos da realidade social. O gosto pela leitura adequado ao consumo de trivialidades cega o agir crítico do sujeito. A leitura deve ser um ato prazeroso sim, mas também, um ato de desafio.

\begin{abstract}
A formação e a transformação do gosto não se dão num passe de mágica. [...] Cabe ao professor romper com o estabelecido, propor a busca e apontar o avanço. Para isso é preciso problematizar o conhecido, transformando-o num desafio que propicie o movimento. [...] Se entendermos que os gostos não são naturais, nem imutáveis, nem sucessivos, mas que se integram ao processo de desenvolvimento em sobressaltos, em que o sujeito vai superando a si mesmo, traçando seu percurso histórico rumo a um objetivo que é sempre provisório e ponto de partida para novos avanços, o trabalho com a leitura da literatura tem de levar em conta essa luta da criança e do jovem (e do professor) inserida na luta e nas contradições da linguagem. É preciso problematizar a noção de carência, geradora de uma pedagogia da facilitação, deslocando o impasse da adequação demagógica ou imposição autoritária para o problema da superação crítica e histórica do gosto, com base numa pedagogia do desafio do desejo. (MAGNAMI, 2009, p. 105).
\end{abstract}

A construção de um bom leitor perpassa, então, pela coerência do professor diante da concepção de uma educação que é embasada numa proposta libertadora. O enfrentamento do texto, juntamente com seus desafios e obstáculos, deve ganhar sentido à medida que direcione para um aguçamento da compreensão e da crítica. Tal processo é possível através das práticas de leitura, movimentando a consciência dos alunos para o adentramento e aprofundamento de

Revista Reflexão e Ação, Santa Cruz do Sul, v. 25, n. 2, p. 102-118, Maio./Ago. 2017. http://online.unisc.br/seer/index.php/reflex/index 
determinados aspectos da realidade, que são veiculados e indiciados por alguns autores e outros não.

\begin{abstract}
Percebemos que o trabalho de seleção e indicação de textos exige cuidados muito especiais por parte dos professores. Por vários motivos: primeiro - quer queiramos ou não, considerando a autoridade da instituição (escola) e do professor, as crianças tendem a assimilar como verdades os referenciais dos textos aos quais são expostos; nestes termos, se o texto for "mentiroso" (estereotipado, conservador etc.), o leitor estará engolindo uma mentira e não adquirindo uma visão objetiva do assunto; segundo - com raras exceções, os textos que compõem os livros didáticos não atendem aos critérios de revelação objetiva da realidade, sequenciação programática ao redor do aprofundamento de temas específicos e adequação ao repertório linguístico e de vivências dos alunos; terceiro - deve existir, como já falamos, uma coerência entre os objetivos propostos para a educação do leitor e os textos relacionados para leitura; acredito que posso matar o potencial discursivo e interpretacional dos alunos com textos superficiais, redundantes, fragmentados e/ou pobres em significação. (SILVA, 2009, p. 65).
\end{abstract}

Portanto, a maior finalidade da leitura é configurar um significado concreto na vida do sujeito. A decodificação pela decodificação não faz sentido, não alimenta o cognitivo, nem a alma. Paulo Freire propõe trazer para dentro da escola o mundo, para que seja possível refletir sobre a realidade e tentar recriá-la. Por isto o ato de ler é antes de mais nada um ato de conhecimento, um ato criador, no qual o leitor é um sujeito com criatividade na construção de seu saber e responsável diante da realidade social da qual ele faz parte.

\title{
4 A LEITURA A PARTIR DA PERSPECTIVA FREIREANA
}

Para Paulo Freire $(1996 ; 2003)$ uma verdadeira educação é aquela que liberta. Educar não é apenas uma transferência da inteligência do objeto ao educando, mas uma provocação no sentido de que, como sujeito cognoscente, torne-se capaz de inteligir e comunicar o inteligido. Isto é, possa conhecer e, conhecendo, transmita ao outro a dinâmica da história que constrói a vida.

Freire (2003) ressalta uma educação fundada na ética, no respeito à dignidade e à própria autonomia do educando. Essa autonomia vai dar ao educando a possibilidade de construir, reconstruir, constatar, para mudar, o que não se faz sem abertura ao risco e à aventura. Tal perspectiva, parte mediante a leitura da realidade das vivências e experiências, a qual envolve prazer, ambiente democrático, diálogo e relação construtiva entre professor e aluno, identificando sua ligação direta com os conceitos e categorias que seu método já abordava na década de 60 do século passado. 
Neste período, a população brasileira era marcada pela pobreza, exclusão, marginalização e grande porcentagem de analfabetos. Uma profunda ideologia de submissão estava instaurada no Brasil. A seu ver tal situação era incabível. Partindo destas condições, juntamente com outras pessoas, enveredou pela construção de uma nova sociedade, na qual a libertação substituiria a exclusão e a dominação.

Reforçou-se aí, a preocupação com a alfabetização de adultos. Não apenas como possibilidade de domínio dos códigos de leitura e escrita, mas como necessidade de ler e interpretar criticamente o mundo, a fim de se situar nele como agente ativo e construtor de si e da história da humanidade. (DAMKE, 1997, p. 143).

Por esta via, Freire (2003) notou que pela leitura pode haver uma emancipação dos homens, isto é, um salto da condição de mero espectador do mundo, onde a submissão é uma característica, para agente ativo e transformador. A preocupação em Freire (2003) era evidenciar o processo pelo qual os seres humanos se apropriam do conhecimento e como o mesmo se constitui como elemento de consciência crítica que oportuniza a identificação do contexto em que está inserido e a transformação dessa realidade.

Percebe-se que Freire (2003) não vê a realidade social e econômica apresentada pelo mercado através do capitalismo como o único modelo. Ao contrário, vislumbra outras vias e alternativas que o ser humano é convocado a pensar e construir, diferentemente do que já se vive. Dessa forma, a leitura da realidade social e suas circunstâncias, como um elemento do processo educativo, reflete outras vias e propostas em que o ser humano emerge como protagonista e autor de seus rumos.

[...] educar é construir, é libertar o ser humano das cadeias do determinismo neoliberal, reconhecendo que a história é um tempo de possibilidades. É um 'ensinar a pensar certo' com quem 'fala com a força do testemunho'. É um 'ato comunicante, co-participado', de modo algum produto de uma mente 'burocratizada'. No entanto, toda a curiosidade de saber exige uma reflexão crítica e prática, de modo que o próprio discurso teórico terá de ser aliado à sua aplicação prática. (FREIRE, 1996, p. 52).

Para tal conjuntura, é imprescindível a alfabetização da pessoa. Neste prisma seu método, de natureza construtivista, é um projeto de vida, de esperança, uma ação educativa na qual há uma busca continua do homem pela dignidade e negação direta de toda e qualquer forma de opressão e injustiça. A leitura para Freire (2003) consiste em ler a realidade com um aguçado olhar e lançar-se às mudanças, tendo em vista que nosso mundo hodierno é marcado pelo abismo da desigualdade. Enfim, conhecer é ler e ler é transformar. E ainda, instiga o ser 
humano a sair do papel de simples "engolidor" de ideias para a desafiante, tarefa de interpretar e reinventar o mundo buscando a verdade e libertando-se dos grilhões do nãomundo. Portanto, o leitor deve ser sujeito. Nesse contexto, reside o entendimento freireano acerca da leitura. Não basta entender somente o que está impresso ou o que se depreende dos signos linguísticos. Mas, urge compreender como os traçados ideológicos se constituem e tecem a realidade social na qual estamos inseridos.

A leitura do mundo precede a leitura da palavra, daí que a posterior leitura desta não possa prescindir da continuidade da leitura daquele. Linguagem e realidade se prendem dinamicamente. A compreensão do texto a ser alcançada por sua leitura crítica implica a percepção das relações entre o texto e o contexto. (FREIRE, 2003, p. 11).

Para ele, a leitura não pode se reduzir a um conjunto de regras de explicação de um texto, como se ele fosse um objeto pronto, acabado, a ser assimilado pelo leitor e, muito menos, a interpretação de códigos que buscam traduzir uma abstrata realidade. Seriam utópicas a concepção de leitura e de ser humano freireano? A resposta pode ser encontrada na própria maneira de viver do educador da libertação. Conforme Damke (1998, p. 41) "Freire é um realista porque é utópico, e utópico e esperançoso porque, para além dos textos, sabe ler a realidade." O que nos permite afirmar com Torres (1979, p. 8) que: “só os utópicos [...] podem ter esperança, só os oprimidos podem libertar-se a si mesmos e libertar seus opressores."

Ler é uma operação inteligente, difícil, exigente, mas gratificante. Ninguém lê ou estuda autenticamente se não assume, diante do texto ou do objeto da curiosidade a forma crítica de ser ou de estar sendo sujeito da curiosidade, sujeito da leitura, sujeito do processo de conhecer em que se acha. Ler é procurar buscar criar a compreensão do lido; daí, entre outros pontos fundamentais, a importância do ensino correto da leitura e da escrita. É que ensinar a ler é engajar-se numa experiência criativa em torno da compreensão. Da compreensão e da comunicação. (FREIRE, 2001, p. 261).

Neste sentido o ser antropológico freireano perpassa, a partir do ato de ler, pela epifania de um novo tipo de sociedade e cidadão. O homem, enquanto sujeito de sua ação, pode fazer com que esta ação deságue numa perspectiva libertadora, que tende, consequentemente, ao desvelamento de um ser utópico e ético, que ao ler a realidade se descobre e transforma o meio que o circunda.

\section{DO LER PARA O SER}


Ler significa decifrar uma notação seja ela qual for. No entanto, tal capacidade não deve ser reduzida a apenas esta função. A ação de ler não se reduz a uma atividade de memorização mecânica de trechos de uma unidade textual. A leitura expande sua definição à medida que a mesma se torna uma ferramenta imprescindível para a posição do ser diante da realidade social que o cerca.

Para tanto, entende-se a leitura como sendo o primeiro passo para a consciência individual do sujeito em decodificar as ideologias que perpassam as estruturas das instituições que predispõem o agir humano (FREIRE, 2003). O ato de ler significa, dessa forma, uma aprendizagem imprescindível a ser desenvolvida pelo ser humano. É imprescindível a leitura da realidade em que estamos inseridos. Entender os aspectos que circundam o sistema social, bem como a condição humana que hoje se propaga, torna-se uma etapa fundamental para a construção crítica do ser humano.

A pessoa é inspirada para a busca constante de sua construção. A formação de sua subjetividade se dá ao longo da história, do contexto social e de sua confrontação diante do outro. Note-se que o ser humano não se configura apenas em sua individualidade biológica, mas necessita do outro e do social para definir sua personalidade.

A Organização das Nações Unidas para a Educação, a Ciência e a Cultura - UNESCO lançou no início do século quatro pilares que fundamentam a educação do século XXI, os quais colaboram para a formação do ser humano diante de sua vida, fundamentando a necessidade do conhecimento e da formação continuada. Os quatro pilares são aprender a conhecer, aprender a fazer, aprender a viver com os outros e aprender a ser.

Com efeito, a apreensão da realidade pela leitura conduz à construção do ser. Tal configuração ganha melhor escopo quando passa pelo entendimento de que a educação é a via constante de formação do sujeito humano.

\footnotetext{
A educação deve contribuir para o desenvolvimento total da pessoa - espírito e corpo, inteligência, sensibilidade, sentido estético, responsabilidade pessoal, espiritualidade. Todo ser humano deve ser preparado, especialmente graças à educação que recebe na juventude, para elaborar pensamentos autônomos e críticos e para formular os seus próprios juízos de valor, de modo a poder decidir, por si mesmo, como agir nas diferentes circunstâncias da vida. (DELORS, 2009. p. 8).
}

Desta forma, os pilares apresentados pela UNESCO configuram-se como uma base sólida para a construção do ser humano na sociedade. Assim, ao despertar o ler o sujeito crítico viabiliza a configuração de um ser que aprende a conhecer, a fazer, a viver com o outro 
e a ser.

Aprender a conhecer: esta dimensão aponta para uma questão fundamental que é a contextualização do que se conhece e do que se aprende. Esta implica uma percepção muito aguçada para compreender como se deu determinado processo em determinado momento.

O segredo de aprender a conhecer é saber relacionar e contextualizar. É perceber
que cada conhecimento pertence a um conjunto e se situa em determinado contexto.
Esse conjunto ou contexto, por sua vez, liga-se a outro conjunto e contexto, e assim
por diante. Perceber essa relação dos dados com seus conjuntos e contextos, dos
conjuntos e contextos entre si, permite à mente situar-se no mar infindo de ondas
passageiras. Em vez de pensar o real como pequenos cacos de conhecimentos,
sabe-o como mosaico maravilhoso. (LIBÂNIO, 2001, p. 19).

Aprender a conhecer é a implicação do conhecimento total e não do conhecimento particularizado. Não se conhece a parte sem antes compreender o todo. Nesta dinâmica dialética se constrói o novo a partir da reconstrução do antigo.

Aprender a fazer: o fazer humano está imbricado da questão ética. Tudo que as pessoas fazem possui uma ressonância na realidade à qual participam. Isto causa um maior comprometimento com as suas ações. Alguns homens produziram as bombas atômicas, outros proporcionaram condições melhores de se viver. Nisto, o aprender a fazer tem de compreender o que é bom e o que é ruim para a humanidade. Aprender a fazer situa-se dentro de:

[...] uma consciência de responsabilidade só é possível com consciência histórica. Assim sendo, o nosso agir histórico adquire gravidade maior. Aprende-se a fazer captando o lado ético de todo agir humano. Implica um senso de responsabilidade. Não existe presente desligado do futuro. Quanto mais cuidarmos de vislumbrar o futuro nos atos presentes, mais aprendemos a fazer. Nossas ações deixam de ser veleidades para adquirir densidade de futuro, de responsabilidade. (LIBÂNIO, 2001, p. 46).

Outro aspecto relevante é que "aprender a fazer não pode, pois, continuar a ter o significado simples de preparar alguém para uma tarefa material bem determinada, para fazêlo fabricar no fabrico de alguma coisa" (DELORS, 2009, p. 04). Significa sim, desenvolver um espírito cooperativo e de humildade na reelaboração conceitual e nas trocas, valores necessários ao trabalho coletivo.

Aprender a viver com os outros: para se relacionar com os outros é fundamental a tolerância. Dela é que emergem o respeito, a confiabilidade e o prazer de se viver em comunidade. Respeitar as individualidades de cada um não é fácil. Exige acima de tudo a valorização da outra pessoa.

Revista Reflexão e Ação, Santa Cruz do Sul, v. 25, n. 2, p. 102-118, Maio./Ago. 2017. http://online.unisc.br/seer/index.php/reflex/index 
O caminho da autêntica formação para viver juntos passa por uma dupla descoberta: a do valor próprio e a do valor dos outros. Sem esse tirocínio do autoreconhecimento do outro não há um viver realmente juntos. Senhores e escravos não convivem. Uns dominam, outros submetem-se. A consciência de uma igualdade radical na diferença dos talentos é a base do viver juntos. (LIBÂNIO, 2001, p. 66).

Uma das formas para aprender a viver juntos é o momento que os educadores podem propiciar aos educandos dentro da sala de aula. Os trabalhos em equipe não possuem fins em si mesmos, mas apenas uma circunstância para refletir acerca de um tema, mas, principalmente, para refletir acerca das condutas que aparecem na formação do grupo.

Assim, tratar a vida numa proposta comunitária e desenvolver uma moralidade acrescida pela experiência do diferente é adentrar no campo da aceitação, da complementação e da revelação daquilo que a vida de cada um pode ser. Esse prisma esmaga a concepção individualista e egocêntrica que se tem da pessoa humana. As várias formas de negação e exclusão só se tonificam quando sai de cena o companheirismo e adentra o egoísmo.

Aprender a ser: esta concepção pressupõe determinações e atitudes do sujeito que deseja buscar uma identidade própria. Esta dá segurança necessária para superar qualquer obstáculo que a vida apresenta. Inclusive a dificuldade que é a de enfrentar a si próprio. Numa palavra, este é o 'pilar' de uma autodescoberta. Segundo Delors (2009, p. 9) aprender a ser faz parte do "desenvolvimento do ser humano, que se desenrola desde o nascimento até à morte, é um processo dialético que começa pelo conhecimento de si mesmo para se abrir, em seguida, à relação com o outro."

Com o avanço da modernidade e a consolidação da globalização constata-se uma cultura que propaga o supérfluo e o descartável, construindo homens e mulheres objetos de um sistema que oprime e silencia. Libânio (2001, p. 90) afirma que "aprender a ser hoje implica necessariamente uma postura crítica diante dessa cultura massificadora, vulgarizada, banalizada."

Aprender a ser é o pilar que sintetiza todos os outros, pois, estrutura-se em torno de si aquilo que deve ser próprio do ser humano, isto é, o sentido ético de responsabilidade pessoal diante de um pensamento autônomo e crítico que busque a iniciativa e crescimento integral da pessoa em relação à sociedade. Assim, a construção do ser exige uma consciência reflexiva e crítica acerca da realidade e, principalmente, um olhar de alteridade diante do outro, daquele que é diferente. Por isso, o completo desenvolvimento do eu se dá perante o grupo social a que se pertence, entendendo a organização do grupo e suas atividades. Nesta dinâmica, no 
bojo das relações interpessoais, influenciamos e somos influenciados (RODRIGUES, 1999). Neste sentido, a configuração crítica do ser se operacionaliza na relação do indivíduo com a configuração social.

\section{CONSIDERAÇÕES FINAIS}

Comumente se ouve falar que a leitura deve provocar um momento de encantamento diante das palavras que saltam do livro, como que se por um momento mágico o leitor ficasse paralisado diante da força das palavras de um texto. O leitor seria apenas um objeto diante do texto. Nada disso reflete a proposta freireana.

A leitura expande sua definição à medida que se torna uma ferramenta imprescindível para a posição do ser diante da realidade social que o cerca. Para tanto, entende-se a leitura, tendo por base Paulo Freire, como sendo o primeiro passo para a consciência individual do sujeito em decodificar as ideologias que perpassam as estruturas das instituições que predispõem o agir humano. A leitura significa, dessa forma, um aspecto imprescindível às aprendizagens de si e do mundo a serem desenvolvidas pelo ser humano.

Para Freire, esta postura revela uma acomodação diante do desafio de entender a totalidade e profundidade do que se lê. O leitor deve ser sujeito. A leitura de um texto provoca muito mais que decifrar o significado das palavras. Deve evocar um espírito investigador e criativo. Desta forma, a leitura de um texto deve proporcionar ao leitor um momento de despertar sua atitude crítica diante do próprio texto. O exercício da leitura deve provocar um leitor crítico para que perceba o contexto e a ideologia que perpassam as ideias, que perpassam as palavras da unidade de sentido.

Assim, ler significa decifrar uma notação seja ela qual for. No entanto, tal capacidade não deve ser reduzida a apenas esta função. "Ler não é puro entretenimento nem tampouco um exercício de memorização mecânica de certos trechos do texto.” (FREIRE, 2001, p. 260). A leitura expande seus significados à medida que a mesma se torna uma ferramenta imprescindível para a posição do ser diante da realidade social que o cerca. E ainda, a ação de leitura promove a construção de um ser humano pautado na capacidade crítica de indagar e se libertar das ideologias que buscam dilacerar a condição ética de construir uma realidade mais equânime e solidaria.

\section{REFERÊNCIAS}


BAUMAN, Zygmunt. Modernidade líquida. Tradução de Plínio Dentzien. Rio de Janeiro: Zahar, 2001.

DAMKE, Ilda Righi. Paulo Freire: o mestre comprometido com o conhecimento, a história e a libertação. Revista de Educação AEC, São Paulo, n. 104, p. 135-148, 1997.

DELORS, Jacques. Os quatro pilares da educação. Disponível em: <http://4pilares.net/textcont/delors-pilares.htm>. Acesso em: 07 set. 2009.

DESCARTES, René. Meditações. Nova Cultural. 1999.

FREIRE, Paulo. Ação cultural para liberdade. 8. ed. Rio de Janeiro: Paz e Terra, 1987. Terra, 1996.

Pedagogia da autonomia: saberes necessários a prática educativa. São Paulo: Paz e

. Carta de Paulo Freire aos professores. In.: Estudos Avançados 15 (41). Disponível em: <http://www.e-educador.com/index.php/artigos-mainmenu-100/160-carta-de-paulofreire-aos-professores $>$. Acesso em: 20 jan. 2017.

. A importância do ato de ler: em três artigos que se completam. 44. ed. São Paulo: Cortez, 2003.

HARVEY, David. Condição Pós-Moderna: uma pesquisa sobre as origens da mudança cultura. São Paulo: Edições Loyola, 1993.

LIBÂNIO, João Batista. A arte de formar-se. São Paulo: Edições Loyola, 2001.

LUCKESI, C.; COSMA, J.; BAPTISTA, N. Fazer universidade: uma proposta metodológica. 6. ed. São Paulo: Cortez, 2001.

MAGNAMI, Maria do Rosário Mortatti. Leitura e Formação do Gosto: por uma pedagogia do desejo do desafio. Diponível em: < www.crariocovas.sp.gov.br/pdf/ideias_13_p101106_c.pdf>. Acesso em: 02 set. 2009.

ORTEGA Y GASSET, José. História como sistema - mirabeau ou o político. Traduzido por Juan A. Gili Sobrinho e Elizabeth Hanna Cortês Costa. Brasília: Universidade de Brasília, 1982.

OXFORD LIVING DICTIONARIES. Post-Truth. Disponível em:

<https://en.oxforddictionaries.com/definition/post-truth>. Acesso em: 20 jan. 2017.

PICANÇO, Zilda Ferreira. A Importância da leitura e sua aplicação no ambiente escolar da Educação de Jovens e Adultos. Disponível em:

<www.crmariocovas.sp.gov.br/lei_a.php?t=002>. Acesso em: 02 set. 2009.

REALE, G.; ANTISERI, D. História da filosofia: do romantismo até nossos dias. v. III. 6. ed. São Paulo: Paulus, 1991. 
SANTOS, Milton. Por uma outra globalização: do pensamento único ao pensamento universal. 11. ed. São Paulo: Editora Record, 2004.

SILVA, Ezequiel Theodoro da. A leitura no contexto escolar. Disponível em: <www.crmariocovas.sp.gov.br/lei_a.php?t=007>. Acesso em: 02 set. 2009.

SOARES, Magda Becker. Língua escrita, sociedade e cultura; relações, dimensões e perspectivas. Revista Brasileira de Educação, ANPED. n. 10. Set/Out/Nov/Dez. 1995.

TORRES, Carlos Alberto. Diálogo com Paulo Freire. Coleção Paulo Freire. v. II. São Paulo: Loyola, 1979. 